\title{
Transmission of food preference does not require socially relevant cues in a mouse strain with low sociability
}

\section{Kimberly J. Zaccaria* and James S. McCasland}

Department of Cell and Developmental Biology, State University of New York Upstate Medical University, Syracuse, NY, USA

${ }^{*}$ Correspondence: zaccarik@upstate.edu

The social transmission of food preference task (STFP) is based on the principle that dietary information can be communicated between rodents during social interaction (Galef and Kennett, 1987). Briefly, a demonstrator mouse consumes a novel flavor, and then freely interacts with an observer mouse. The observer mouse is now "socially cued" toward that flavor, and will prefer it in a choice paradigm over another novel "un-cued" flavor. Socially relevant cues are required for this transmission of food preference in adult rats (Galef and Kennet, 1987) and C57BL/6J mice (Ryan et al., 2008). This evidence indicates that the STFP task is an appropriate measure of social communication in rodents. Since impaired communication is a diagnostic criterion for autism (DSMIV), several studies have utilized this protocol to investigate autistic-like behavior in mice (Boylan et al., 2007; McFarlane et al., 2008; Ryan et al., 2010).

We performed the STFP task, as previously described (McFarlane et al., 2008), to evaluate social communication in mice with a mixed C57BL/6J 129S3/SvImJ background (B6129S3) (Zaccaria et al., 2010).
This mouse strain exhibits low social approach and lack of preference for social novelty (Zaccaria et al., 2010). Therefore, it was surprising that B6129S3 mice consumed significantly more cued than noncued food $\left(t_{38}=2.41, p<0.05-\right.$ Figure 1A). According to McFarlane et al. (2008), this indicates intact social communication, which is difficult to reconcile with strainspecific low sociability.

Our findings could be explained if transmission of preference was in response to olfactory cues alone, and did not require the social component of the task. We tested this hypothesis by performing a non-social transmission of food preference (NSTFP) task, which removed socially relevant cues (Zaccaria et al., 2010). The STFP protocol was modified by substituting a novel-scented object (interlocking blocks) for the novelscented mouse. In this NSTFP task, B6129S3 mice ate significantly more cued than noncued food $\left(t_{28}=2.12, p<0.05-\right.$ Figure 1A), just as in the STFP task. Total consumption per mouse was significantly greater during the STFP task, likely because mice were $\sim 2$ months older (STFP $=0.55 \pm 0.09 \mathrm{~g}$, $\left.\mathrm{NSTFP}=0.31 \pm 0.05 \mathrm{~g}, t_{33}=3.36, p<0.01\right)$.

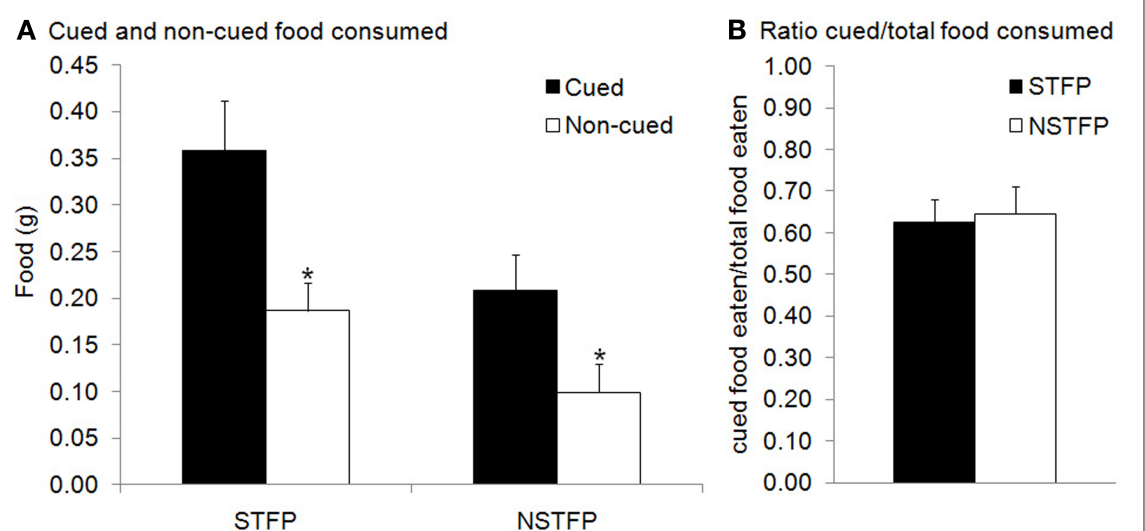

FIGURE 1 | Food consumption during the STFP and NSTFP tasks. (A) In both tasks, B6129S3 mice consumed significantly more cued food than non-cued food ( $\left.{ }^{*} p<0.05\right)$. (B) To control for differences in total food intake, the ratio of cued food eaten to total food eaten was calculated. This ratio was $>60 \%$ for both tasks (B adapted from Zaccaria et al., 2010).
To control for this difference in overall intake, we calculated the ratio of cued food to total food consumed. This ratio was $>60 \%$ in both tasks (Figure 1B, Zaccaria et al., 2010), demonstrating that mice developed preference for the cued food both with and without socially relevant cues. These results indicate that social interaction is not necessary for transmission of food preference in this background strain, contradicting findings from the more social C57BL/6J mouse strain (Ryan et al., 2008). This discrepancy is likely due to differences in strain-specific levels of sociability.

These findings highlight the importance of isolating the effects of olfactory vs. social cues when evaluating transmission of food preference. To confirm that transmission requires social communication, the NSTFP task should be performed as a control when evaluating positive results from the STFP task. This appears to be critical in strains with low sociability.

These findings also reveal a previously undescribed abnormality in social communication among mice. The STFP task can only evaluate whether transmission of food preference occurs in a social setting - not whether social cues are actually required. By performing the NSTFP task, we also evaluated whether the presence of a novel food in a non-social setting can lead to similar transmission. We found that our low-sociability mice do not distinguish between social and non-social cues for determining food preference. In a natural habitat, this NSTFP could be severely maladaptive. To learn what foods are safe to eat, rodents rely heavily on communication of dietary information through social contact (Valsecchi et al., 1996). In this context, choosing food based on non-social cues (i.e., presence of a food on an inanimate object) could place a rodent's survival at risk. By this logic, we propose that lack of discrimination between social and non-social cues for transmission of food preference is a novel example of impaired communication in mice. 


\section{ACKNOWLEDGMENTS}

This work was supported by the Golisano Children's Hospital/Children's Miracle Network award \#8801 and Intramural Hendricks award \#130230-16. We would like to thank Ginny Grieb for expert technical assistance.

\section{REFERENCES}

Boylan, C. B., Blue, M. E., and Hohmann, C. F. (2007). Modeling early cortical serotonergic deficits in autism. Behav. Brain. Res. 176, 94-108.

Galef, B. G. Jr., and Kennett, D. J. (1987). Different mechanisms for social transmission of diet preference in rat pups of different ages. Dev. Psychobiol. 20, 209-215.
McFarlane, H. G., Kusek, G. K., Yang, M., Phoenix, J. L., Bolivar, V. J., and Crawley, J. N. (2008). Autism-like behavioral phenotypes in BTBR $\mathrm{T}+\mathrm{tf} / \mathrm{J}$ mice. Genes Brain Behav. 7, 152-163.

Ryan, B. C., Young, N. B., Crawley, J. N., Bodfish, J. W., and Moy, S. S. (2010). Social deficits, stereotypy and early emergence of repetitive behavior in the C58/J inbred mouse strain. Behav. Brain Res. 208, 178-188.

Ryan, B. C., Young, N. B., Moy, S. S., and Crawley, J. N. (2008). Olfactory cues are sufficient to elicit social approach behaviors but not social transmission of food preference in C57BL/6J mice. Behav Brain. Res. 193, 235-242.

Valsecchi, P., Singelton, G. R., and Prince, W. J. (1996). Can social behaviour influence food preference of wild mice, Mus domesticus, in confined field populations? Aust. J. Zool. 44, 493-501.
Zaccaria, K. J., Lagace, D. C., Eisch, A. J., and McCasland, J.S. (2010). Resistance to change and vulnerability to stress: autistic-like features of GAP43 deficient mice. Genes Brain Behav. [Epub ahead of print].

Received: 03 September 2010; accepted:07 September 2010; published online: 22 September 2010.

Citation: Zaccaria KJ and McCasland JS (2010)

Transmission of food preference does not require socially relevant cues in a mouse strain with low sociability. Front. Behav. Neurosci. 4:164. doi: 10.3389/fnbeh.2010.00164 Copyright (c) 2010 Zaccaria and McCasland. This is an open-access article subject to an exclusive license agreement between the authors and the Frontiers Research Foundation, which permits unrestricted use, distribution, and reproduction in any medium, provided the original authors and source are credited. 